\title{
ASPHYXIA ACTIVATES P65 AND INDUCES VEGF-A GENE EXPRESSION IN RETINA AND CHOROID FROM NEWBORN PIGLETS
}

\author{
R. Solberg ${ }^{1}$, A. Arduini ${ }^{2}$, J. Escobar ${ }^{3}$, O. Saugstad ${ }^{1}$, V. Maximo ${ }^{4}$
}

${ }^{1}$ Pediatric Research Institute, University of Oslo, Oslo, Norway, ${ }^{2}$ Physiology, University of Valencia, ${ }^{3}$ Health Research Institute (I.I.S. La Fe), ${ }^{4}$ Division of Neonatology, University and Polytechnic Hospital La Fe,

Valencia, Spain

Objective: Exposure to lower oxygen causes oxidative stress and promotes angiogenesis. Asphyctic neonates have shown higher cord-blood vascular endothelial growth factor (VEGF). We hypothesized that retina and choroid having a different circulatory regulation (choroid lacks vascular auto-regulation) would acutely stimulate angiogenesis in response to short and severe hypoxemia.

Methods: Retina/choroid were obtained from hypoxic (FiO2:8\% x $30 \mathrm{~min}$ ) newborn piglets resuscitated with $21 \% \mathrm{O} 2$ and controls (ventilated with $21 \% \mathrm{O} 2$ ) at $6 \mathrm{~h}$ after birth. Vegfa mRNA expression was determined by real-time PCR. Protein level of hypoxia inducible factor-1alpha (HIF-1alpha), Vegf, phosphorylated p65 (S539), p65, and Gapdh (housekeeping gene) were studied by western blotting.

Results: Vegfa mRNA expression in retina and choroid significantly increased during hypoxia $(\mathrm{p}<0.01 \mathrm{vs.}$ control). At protein level, Hif-1 $\alpha$ did not change significantly with hypoxia or re-oxygenation. Vegf protein did not increase in retina or choroid with hypoxia or re-oxygenation. P65 was significantly more phosphorylated in response to hypoxia ( $\mathrm{p}<0.05$ vs. control), and restored to baseline after re-oxygenation just in retina. Total levels of p65 increased in choroid after $6 \mathrm{~h}$ of resuscitation ( $\mathrm{p}<0.05 \mathrm{vs}$. control).

\section{Retina}

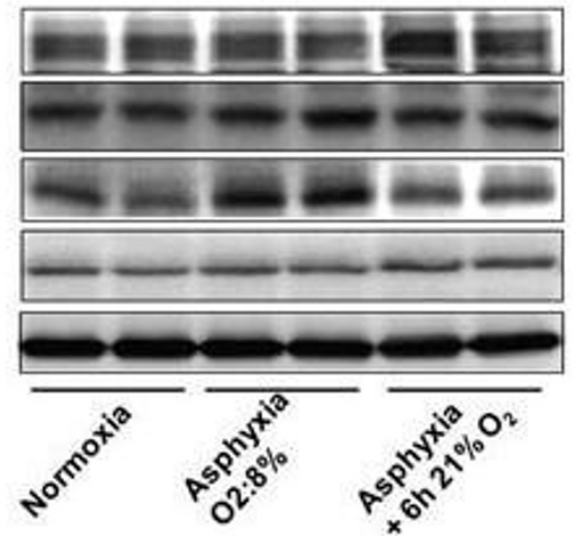

Choroid

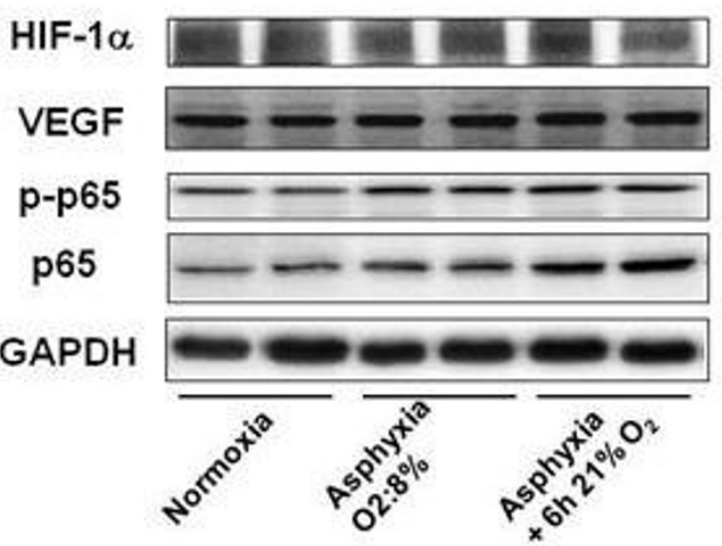

[RETINA AND CHOROID WESTERN BLOTTING]

\section{Conclusions:}

(i) Short-term hypoxemia promotes p65 activation in retina and choroid.

(ii) Vegf-mRNA expression is not Hif-1 $\alpha$-dependent but secondary to p65-activation.

(iii) Angiogenic factors' synthesis has not been achieved due to time elapsed between hypoxemia and tissue extraction. 